\title{
A SMALL, PRIMARY SOLAR-ELECTRIC PROPULSION DEMONSTRATION SATELLITE
}

\author{
Hans F. Meissinger* \\ Microcosm, Inc. \\ Torrance, $\mathrm{CA}$
}

\begin{abstract}
Interest in the application of primary solar-electric propulsion to high-energy Earth orbital and deep-space missions has increased in recent years because of its inherent propellant economy and the promise of greatly enhanced payload weight capacity for a given vehicle launch weight. This paper describes a small, low-cost electric propulsion demonstration satellite, capable of ascending from low altitude to geosynchronous orbit in ten months or less, using only about $1 \mathrm{~kW}$ of propulsive power. Based on available technology of ion thrusters and lightweight solar arrays, and using elements of current light satellite design, this mission is of timely interest as a step in the evolution of future operational electric propulsion transfer vehicles. Generic data on system and mission design for this demonstration vehicle are presented along with relevant literature references.
\end{abstract}

\section{Introduction}

$\mathbf{P}$ rimary solar-electric propulsion (SEP) for fuel-efficient satellite orbit raising to geosynchronous or half-geosynchronous altitudes has attracted new interest in recent years, for example, in a project currently being sponsored by the U.S. Air Force Space Division. The advantage of a large payload weight increase is gained at the expense of long-duration orbital ascent. The technology required for such missions is available today, if a reasonably small solar-electric power source is considered. However, not since the early Space Electric Rocket Test flights (SERT I and II) performed by NASA in the 1960s and early 70 s have there been any long-term demonstrations of primary ion propulsion in space. This paper describes the concept of a small, low-cost demonstration satellite which appears to be of timely interest as a step in the evolution of SEP technology and mission design.

Recent studies have considered SEP transfer stages requiring at least 50 to $100 \mathrm{~kW}$ solar-array power for long-duration orbitraising of payloads in excess of $15,000 \mathrm{lb}$ and, therefore, entailing some development risk and high program cost (Reference 1). A less demanding mission with the objective of SEP technology demonstration, designated as Electric Insertion Technology Experiment (ELITE), currently is being projected by the Air Force. A comprehensive analysis of this mission was presented at the July 1990 International Electric Propulsion Conference by De Vincenzi et al (Ref. 2). A related paper was presented at the July 1989 Joint Propulsion Conference by Cohen (Ref. 3). These papers contain important references to the current state of electric propulsion technology and its evolution over the last decades. They also contain comprehensive parametric design and mission performance data.

The concept proposed in this paper is at the extreme low end of the scale of SEP spacecraft. It is intended as a precursor system using only about $1 \mathrm{~kW}$ of propulsive power,

* Senior System Engineer; Associate Fellow, AIAA. 
suitable to support ion engine thrust of about 10 $\mathrm{mlb}$, at a specific impulse of $3000 \mathrm{~s}$ and a total propulsion efficiency of 65 percent. The satellite gross weight is in the 450 to $550-1 \mathrm{~b}$ range. Arc jet propulsion, at 800-1000 s specific impulse and 30 percent efficiency yielding a somewhat higher thrust force per unit propulsive power could also be used, but is omitted from further discussion in this paper. The ELITE mission references mentioned above contain detailed parametric electric thruster system and mission performance characteristics for both ion and arcjet thrusters with focus on the latter type. The ELITE spacecraft is expected to operate in the 10-to$15-\mathrm{kW}$ power range.

Technology objectives of the proposed low-cost demonstration mission include verification of engine performance and endurance; orbit-raising performance; avoidance of eccentricity build-up due to eclipses at low altitude; optimal or near-optimal solar array pointing modes; and navigation and guidance performance. A small payload package to record propulsion performance and interaction effects would be a principal part of the payload, as well as science sensors for Earth observation and measurement of radiation environment effects at intermediate altitudes.

In view of the long duration of this mission (up to ten months) the use of autonomous navigation and guidance is envisioned to minimize the need for ground support. An autonavigation system such as the Autonomous Navigation System being developed by Microcosm, Inc. based on the Barnes Engineering Dual Cone Scanner, would provide the orbit position and three-axis attitude. The alternative of navigation by GPS signals does not readily provide the satellite artitude, and opportunities for GPS contact decrease in the higher altitude region of the ascent trajectory.

The small SEP satellite can be readily accommodated as a piggy-back payload on a Shuttle launch, using only about 3 percent of the weight capacity, at an accordingly small share of the launch cost. It could also be launched into low-altitude orbit by a Delta-class ELV.

The paper will describe generic mission data, a conceptual spacecraft configuration with weight and power estimates, as well as mission constraints and performance trades. Some of the mission and system characteristics of Reference 2 also apply to the proposed mission and system concept. In addition, much of the material covered in the existing literature on electric propulsion, such as References $4,5,6$, 7 , will be directly applicable to the new demonstration mission concept.

\section{Demonstration Mission Objectives}

A principal near-term application of electric propulsion (EP) is orbit raising to high Earth orbital altitude, since SEP spacecraft can carry a much larger payload mass for a given launch weight than chemical propulsion stages. Return of the EP transfer vehicle with or without an attached payload also is envisioned in view of the high total impulse capacity of EP systems (Ref. 1).

A primary demonstration objective will be to perform a spiral ascent to synchronous, or half-synchronous altitude. This includes a change from the initial orbit inclination to zero, in the former, or to $55^{\circ}$ in the latter case, which is the inclination of the 12-hour GPS satellite orbits.

The plane change is achieved by thrusting in forward direction but with an out-of-plane component to the left or right of the orbit plane. Reversal of the out-of-plane direction occurs at midpoints between the nodes of the current and the target orbit planes (Reference 8). This requires continuous knowledge of the spacecraft orbit and its orbital position.

Future applications of SEP spacecraft will include interplanetary missions initially spiralling up to Earth escape and finally spiralling down into orbit around the target planet (Reference 4, 9). The very low thrust available from the SEP system is much more effective in the heliocentric than in the planetocentric phase, not only because of the orders of magnitude smaller gravity environment in which the system will operate-near Earth the Sun's gravity is only $6 \cdot 10^{-4}$ times the Earth's surface gravity-but also because prolonged thrust phases do not necessarily lead to greatly extended interplanetary transfer times. The proposed technology demonstration mission 
thus serves as a precursor to geocentric orbit raising missions, as well as to future deep-space SEP applications. In this regard, the projected demonstration time is seen as a desirable aspect in view of the long thrust duration requirements of deep-space missions.

The diagnostic instrumentation package to be carried by the demonstration spacecraft will monitor thruster performance and possible degradation, and observe any malfunctions. In the case of a thruster failure, the demonstration flight will be continued with a spare thruster.

An important objective will be the demonstration of spacecraft roll maneuvers that are required to maintain optimal solar array pointing. Interaction with gravity gradient torques will be observed to derive criteria for spacecraft design economy (see Section 5).

The mission also will demonstrate techniques to enhance orbit-raising effectiveness by minimizing drag at low altitude and thereby increasing the average thrust-to-drag ratio, and hence accelerating the ascent beyond the residual drag region. The trade between the power loss resulting from feathering the array panels (orienting them edgewise to the atmospheric flow) and the gain in thrust-to-drag ratio tends to be very favorable, permitting initiation of the mission at lower altitude (e.g., from typical Shuttle orbits) without requiring a chemical propulsion boost. Lowering the eclipse duration of the initial part of the ascent by selecting a favorable launch time also helps to accelerate the initial ascent out of the drag region. Thus, the demonstration can provide verification of predicted effectiveness enhancements (see Section 6).

The objective of demonstrating performance of a full-sized SEP system and its interactions with a representative spacecraft subsystem complement is beyond the scope of this low-cost SEP orbit-raising mission. Rather, this will be the objective of the much larger, more representative ELITE SEP technology verification program. However, this should not diminish the merit of the small precursor mission with its significant cost and schedule advantages.

\section{Mission Performance}

Continuous thrusting in spiral ascent to high altitude implies long thrust durations that increase approximately in an inverse proportion with the thrust acceleration of, say, 20 micro-g and a total velocity requirement of $16,000 \mathrm{ft} / \mathrm{s}$ to go from a low-altitude, inclined orbit to geosynchronous equatorial orbit. Allowing for gravity loss of the low-thrust spiral ascent mode, a total flight time of nearly 300 days is required. This acceleration is selected as suitable for the low-powered demonstration mission. This acceleration corresponds to 10 milli-lb of thrust applied to a spacecraft of $500-1 \mathrm{~b}$ average weight. The ion engine assumed here requires a propulsive power of

$$
P=2.18 F I_{s p} / \eta
$$

where

$$
\begin{aligned}
F & =10 \mathrm{mlb} \\
I_{s p} & =3000 \mathrm{~s} \\
\eta & =65 \text { percent (thruster } \\
& \text { efficiency, a function of } I_{s p} \text { ) }
\end{aligned}
$$

A gross solar array power of about $1.2 \mathrm{~kW}$ is used to support spacecraft engineering subsystems and payload equipment in addition to the SEP system.

The required propellant weight is determined by

$$
\begin{aligned}
W_{\text {prop }} & =F T I_{s p} \\
& =\left(10^{-2}\right)(300)(86,400) / 3000 \\
& =86 \mathrm{lb}
\end{aligned}
$$

Thus, with an average spacecraft weight of $500 \mathrm{lb}$, the initial weight is $545 \mathrm{lb}$ and the burnout weight is $455 \mathrm{lb}$.

Figure 1 shows the variation of transfer time to GEO and half-GEO altitudes as a function of propulsion power for several values of specific impulse and the corresponding ion engine efficiency in accordance with the approximate relationship:

$$
T=2.18 I_{s p} W_{a v e} \Delta V / 86,400(P \eta g)
$$

In this equation the average weight, $W_{a v e}$ is related to the initial weight, $W_{i}$, the burnout weight, $W_{o}$ and the propellant weight, $W_{p r o p}$, and varies with power, as follows:

$$
W_{\text {ave }}=\left(W_{i}+W_{e}\right) / 2
$$




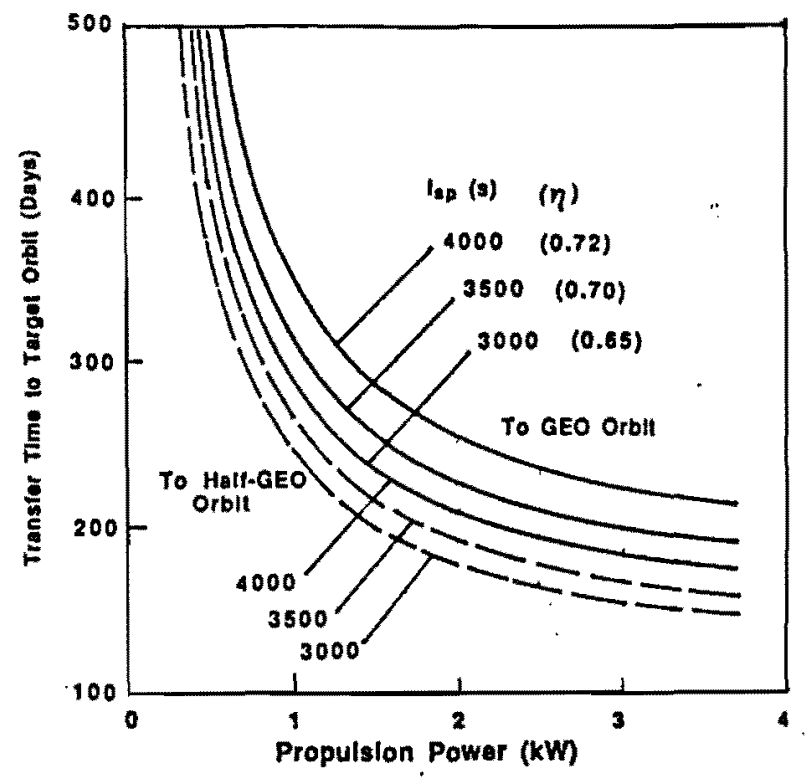

Fig. 1. Variation of Transfer Time with SEP Power.

and

$$
\begin{aligned}
W_{e} & =W_{i}-W_{p r o p} \\
& =W_{s c}+P / \alpha_{s}-P \eta T 72.18 I_{s p}^{2}
\end{aligned}
$$

where the term $\alpha_{s}$ is the SEP system specific power (in W/lb). It is strongly influenced by the SEP technology development status. For the time frame of the proposed mission (the late $1990 \mathrm{~s}), \alpha_{s}$ is assumed to range from 15 to $30 \mathrm{~W} / \mathrm{lb}$. In addition, the solar array specific power must be taken into account. Assuming $10 \mathrm{~W} / \mathrm{lb}$ as typical for a lightweight solar array, the total specific power is reduced to the range of 6 to $7.5 \mathrm{~W} / \mathrm{lb}$. This corresponds to a total SEP weight, including the solar array, ranging from about 130 to $170 \mathrm{lb}$ for a propulsive power requirement of about $1 \mathrm{~kW}$.

With these data and $\Delta V=16,000 \mathrm{ft} / \mathrm{s}$ total impulse for ascent to GEO, the transfer time is expressed by

$$
T=\frac{3.45+2.82 P}{P}\left(\frac{I_{s p}}{\eta}\right)
$$

The transfer times shown in Fig. 1 were obtained by simplified analysis and do not reflect the influence of eclipses and residual atmospheric drag at low altitudes. Detailed quantitative results that include these effects are given in Refs. 1 and 2 . The main objective here is to indicate the general character of the power vs. transfer time trade. In the proposed precursor mission the exact transfer time is not a key consideration.

In an earlier article by the author (Reference 10), it was pointed out that there is a diminishing return in mission performance as a result of increasing the propulsive power and, hence, the thrust force. Expressed in simplified form, the EP thrust acceleration varies with power as shown by the relation

$$
a=F / m=k_{1} P /\left(k_{2}+k_{3} P\right):
$$

This is shown in Fig. 2. The slope of this curve

$$
\mathrm{d} a / \mathrm{d} P=k_{1} k_{2} /\left(k_{2}+k_{3} P\right)^{2}
$$

decreases rapidly from its value, $k_{1} / k_{2}$, at $P=$ $O$ as $P$ is increased. For large values of $P$ the acceleration approaches a limiting value, $k_{1} / k_{3}$, asymptotically. These facts indicate the advantage of planning an early SEP demonstration mission at very low power level. Doubling $P$ from the assumed nominal value $(1.0 \mathrm{~kW})$ would increase the average acceleration from 20 micro-g by only 43 percent and reduce the ascent time to GEO from 300 to 210 days. Tripling $P$ would increase the acceleration by 66.5 percent and reduce the ascent time to 180 days (see Fig 1). 


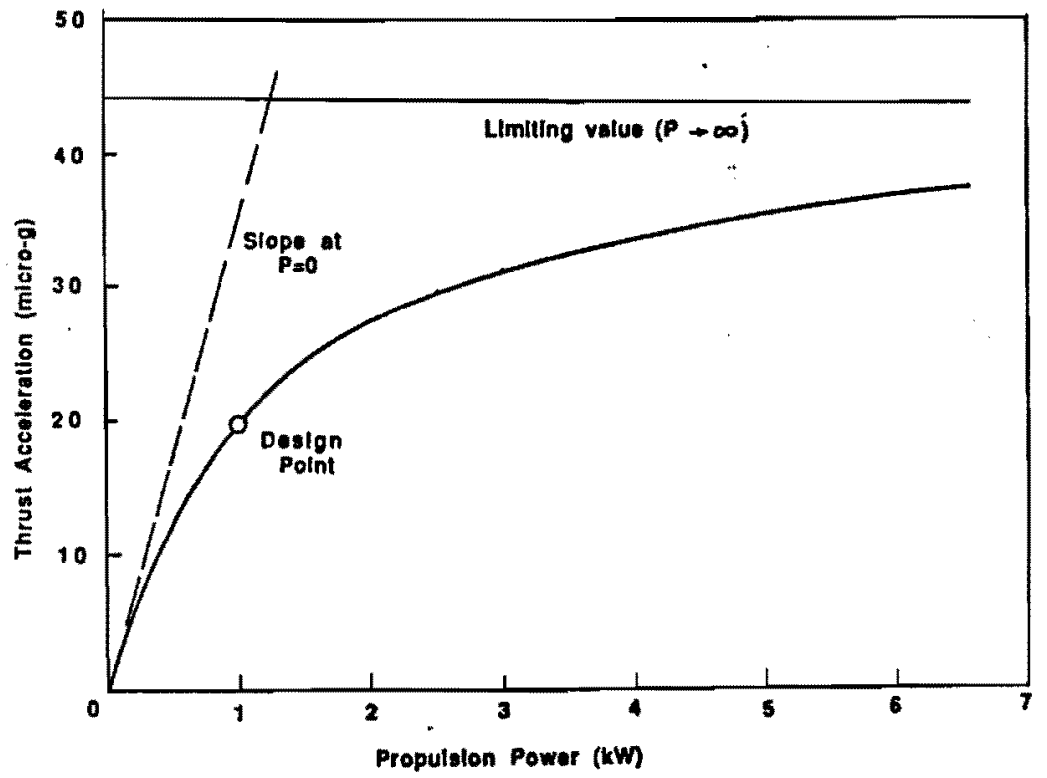

Fig. 2. Thrust Acceleration vs. SEP Power.

Table 1 gives a comparison of the shown are rough estimates, but clearly indicate proposed demonstration mission characteri- the useful role the proposed concept may stics with other operational missions previously assume in the evolution of SEP technology investigated or currently projected. The data development and application.

Table 1. Some SEP Mission and Spacecraft Projects (Past and Current).

\begin{tabular}{|c|c|c|c|c|c|c|c|}
\hline \multirow[b]{2}{*}{$\begin{array}{l}\text { Name and } \\
\text { Sponsor }\end{array}$} & \multirow[b]{2}{*}{ Mission Type } & \multicolumn{4}{|c|}{ Estimated } & \multirow{2}{*}{$\begin{array}{l}\text { EP } \\
\text { Englne } \\
\text { Type 1 } \\
\text { (Prop. } \\
\text { Type) } \\
\end{array}$} & \multirow[b]{2}{*}{$\begin{array}{c}\text { Status/ } \\
\text { Comments }\end{array}$} \\
\hline & & $\begin{array}{l}\text { SEP } \\
\text { Power } \\
\text { KW }\end{array}$ & $\begin{array}{l}\text { Gross } \\
\text { Welght } \\
\text { w/o P/L } \\
\text { (lb) }\end{array}$ & $\begin{array}{c}\text { Payload } \\
\text { Welght } \\
\text { (Ib) }\end{array}$ & $\begin{array}{l}\text { Develop. } \\
\text { Cost } \\
\text { Brackets } \\
(S M)\end{array}$ & & \\
\hline $\begin{array}{l}\text { Space Electric } \\
\text { Rocket Test } \\
\text { (SERT II) } \\
\text { NASALERC }\end{array}$ & $\begin{array}{l}\text { - Technology } \\
\text { demonstr. } \\
\text { - Low-Earth orbit } \\
\text { Test }\end{array}$ & 1.5 & $\begin{array}{l}\sim 1500 \\
\text { (attached } \\
\text { to Agena } \\
\text { stage) }\end{array}$ & -. & (not known) & Ion $(\mathrm{Hg})$ & $\begin{array}{l}\text { - Successful } \\
\text { flight demo. } \\
\text { (>1yr. } \\
\text { duration) in } \\
\text { early } 70 \mathrm{~s}\end{array}$ \\
\hline $\begin{array}{l}\text { Solar-El.- } \\
\text { Prop. Stage } \\
\text { (SEPS) } \\
\text { NASAMSFC }\end{array}$ & $\begin{array}{l}\text { - Transfer stage } \\
\text { - Near- } \\
\text { Earth/Deep- } \\
\text { space }\end{array}$ & -30 & $\begin{array}{l}2,200 \\
6,500\end{array}$ & $\begin{array}{l}2,500- \\
8,000\end{array}$ & $>100$ & lon $(\mathrm{Hg})$ & $\begin{array}{l}\text { - Studies and } \\
\text { initial } \\
\text { devolopment } \\
\text { in late } 70 \mathrm{~s}, \\
\text { early } 80 \mathrm{~s} \\
\text { - Discontinued } \\
-1982\end{array}$ \\
\hline $\begin{array}{l}\text { EP Orbit } \\
\text { Transfer } \\
\text { Vehicle } \\
\text { (EPOTV) } \\
\text { USAF / SSD }\end{array}$ & $\begin{array}{l}\text { - Transfer stage } \\
\text { - Ascent \& return } \\
\text { - GEO. HGEO }\end{array}$ & 50 to 100 & $\begin{array}{c}10,000 \text { to } \\
15,000\end{array}$ & $\begin{array}{c}10,000 \text { to } \\
15,000\end{array}$ & $>300$ & $\begin{array}{c}\text { lon } \\
\text { (Xenon) }\end{array}$ & $\begin{array}{l}\text { - Studies since } \\
\text { late } 80 \text { s } \\
\text { - Projected for } \\
2000 \text { to } 2010 \\
\text { time frame }\end{array}$ \\
\hline $\begin{array}{l}\text { Electric } \\
\text { Insertion } \\
\text { Technology } \\
\text { Experiment } \\
\text { (ELITE) USAF } \\
\text { / Phillips Lab. }\end{array}$ & $\begin{array}{l}\text { - Technology } \\
\text { verification } \\
\text { - Interaction } \\
\text { measurements }\end{array}$ & 10 to 15 & $\begin{array}{c}6,000 \text { to } \\
8,000\end{array}$ & $>100(?)$ & (Not known) & $\begin{array}{c}\text { Arcjet } \\
\left(\mathrm{NH}_{3} \text { or }\right. \\
\left.\mathrm{H}_{2}\right)\end{array}$ & $\begin{array}{l}\text { - System } \\
\text { definition } \\
\text { started } \\
\text { - Projected for } \\
\text { late } 90 \text { s }\end{array}$ \\
\hline $\begin{array}{l}\text { Proposed } \\
\text { small SEP } \\
\text { Techn. } \\
\text { spacecraft } \\
\end{array}$ & $\begin{array}{l}\text { - Technology } \\
\text { demonstration } \\
\text { precursor } \\
\text { - Ascent to GEO }\end{array}$ & -1 & 550 & 25 & 25 & $\begin{array}{l}\text { lon } \\
\text { (Xenon or } \\
\text { Krypton) }\end{array}$ & $\begin{array}{c}\text { Subject of this } \\
\text { paper (Data } \\
\text { are rough } \\
\text { estimates) }\end{array}$ \\
\hline
\end{tabular}




\section{Spacecraft and Subsystem Characteristics}

A key to major cost and weight savings, and to reducing the system development time, is to adopt elements of existing small satellite designs (e.g., "Light Sat") to the mission. However, rather than adding electric thrusters, power processing units (PPU), propellant tankage, and a pair of (comparatively) large solar panels to an existing small spacecraft bus, the design process starts with the SEP hardware, derived from current development programs and determines the required spacecraft structure and engineering subsystems that are to be added. A generic spacecraft weight breakdown is given in Table 2 , based on data in References 11 and 12. The gross weight at launch is $545 \mathrm{lb}$ (see Section 3), including a 20-percent SEP and spacecraft subsystem weight margin. About $90 \mathrm{lb}$ of propellantXenon or Krypton-are included in this weight. Thus the average weight during the mission is about $500 \mathrm{lb}$. The electric thrusters, assumed to be ion engines, are to be operated one at a time, each having a nominal thrust of $10 \mathrm{mlb}$ (at $I_{s p}=3000 \mathrm{sec}$ and 65 percent efficiency). With an assumed 95percent PPU efficiency, this requires an electric propulsion input power of $1.06 \mathrm{~kW}$. Assuming 120-W spacecraft subsystem and payload equipment power plus battery recharge power during the 62-percent daylight portion of the initial low-altitude orbit leads to a mean solar array power requirement $P_{m}=1.27 \mathrm{~kW}$. Solar array degradation incurred during the extended radiation belt passage early in the mission is estimated to be about 30 percent. The required higher power level at the beginning of life (BOL), is determined from $P_{m}$ by taking the estimated power degradation into account, using the relation $\left(P_{1}+0.7 P_{1}\right) / 2=$ $P_{m}$, where $P_{1}$ is the BOL power. The resulting value of $P_{1}$ is $1.176 P_{m}$ or $1.5 \mathrm{~kW}$.

Table 2. Spacecraft Welght and Power Breakdown (Rough First Estimates).

\begin{tabular}{|c|c|c|}
\hline Subsystem & Weight (Ib) & Power (W) \\
\hline $\begin{array}{l}\text { Spacecraft Bus } \\
\text { Structure \& Mechanisms } \\
\text { Comm. \& Data Handling } \\
\text { GN\&C (ind. computer) } \\
\text { Thermal } \\
\text { Power Distr. and Batteries } \\
\text { Payload (Diagnostics) } \\
\text { Bus Subtotal }\end{array}$ & $\begin{array}{l}75 \\
25 \\
30 \\
10 \\
40 \\
25\end{array}$ & $\begin{array}{rrr}20 & & \\
35 & & \\
30 & & \\
5 & & \\
15 & & \\
15 & & \\
& 120 \quad(206)^{(1)}\end{array}$ \\
\hline $\begin{array}{l}\text { SEP Elements } \\
\text { Ion Thrusters (3) } \\
\text { PCUs(3) } \\
\text { Tankage } \\
\text { Solar Array } \\
\text { SEP Subtotal } \\
\text { S/C Subtotal } \\
\text { Margin }(20 \% \text { of SK Dry Weight) }\end{array}$ & $\begin{array}{rr}40 & \\
20 & \\
15 & \\
100 & \\
& 175 \\
& 380 \\
& 75\end{array}$ & $\begin{array}{l}1010 \\
50 \\
\\
\text { See }^{(2)} \\
1060 \\
1180(1270)^{(1)}\end{array}$ \\
\hline $\begin{array}{l}\text { S/C Total } \\
\text { Propellant } \\
\text { Launch Weight } \\
\text { (Mean Weight During Ascent) }\end{array}$ & $\begin{array}{l}455 \\
90 \\
545 \\
(500)\end{array}$ & \\
\hline
\end{tabular}

(1) increase for battery recharge cycle

(2) Solar array mean power (BOL power $=1.50 \mathrm{KW})$ 
Figure 3 shows a conceptual spacecraft configuration. Major components are called out in the illustration. The solar panels, placed on opposite sides of the spacecraft body, are deployed in accordion fashion, using extendable booms of the BISTEM type. The deployment is similar to that of the HEAO solar array but uses lightweight structural design, since array stiffness is not an important consideration here. The panels are articulated for single degree-of-freedom rotation of $\pm 180^{\circ}$ around the spacecraft $y$ axis. For continuous optimal array pointing to the Sun a second rotation is provided by periodic spacecraft roll motions, once per revolution, (see Section 5).

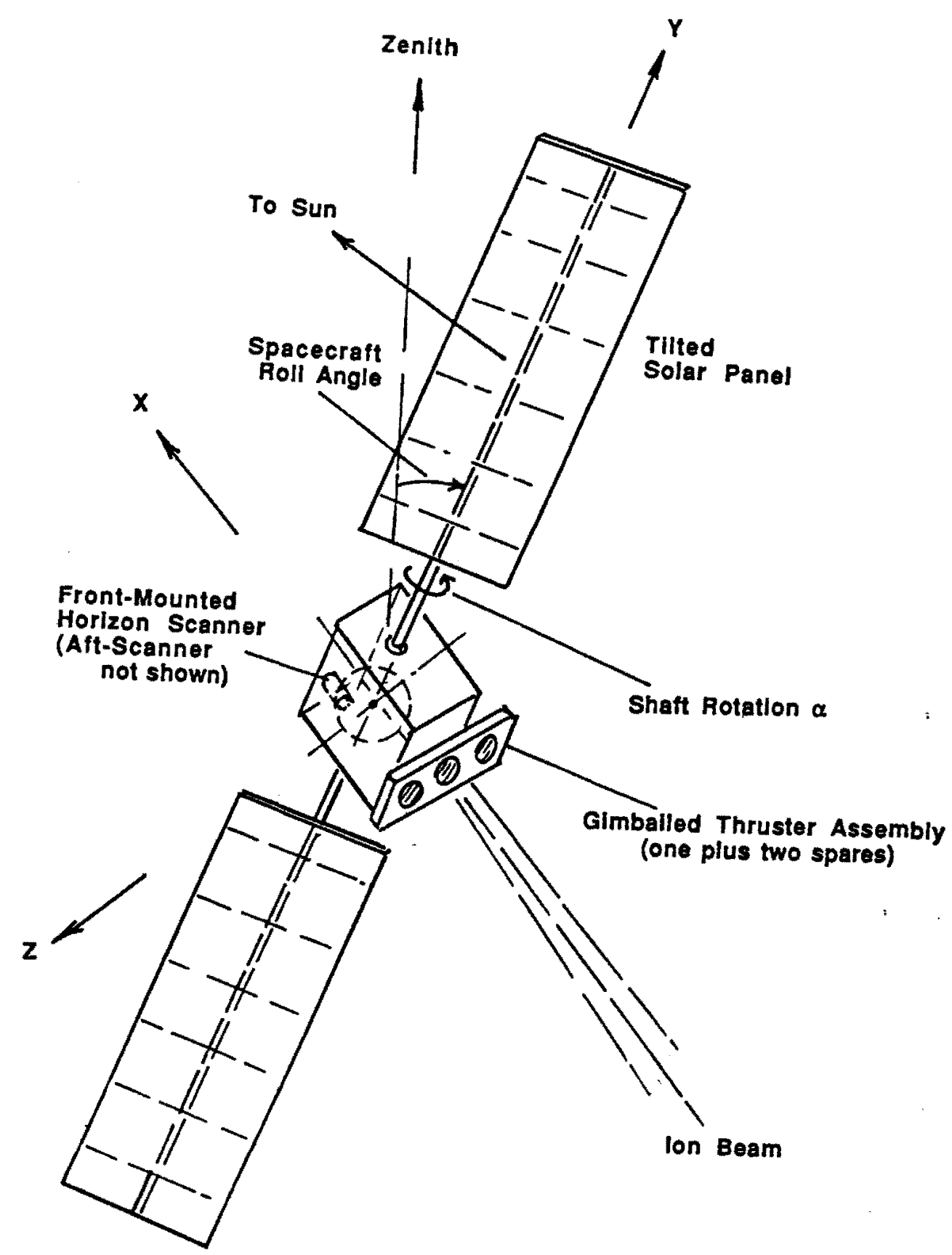

Fig. 3. Representative Spacecraft Configuration. Integral electric propulsion, used in transfer to synchronous orbit and on station. 
The Sun-pointing implementation shown in Fig. 3 is preferred over an alternative one that is illustrated in Fig. 4, which provides a twodegree-of-freedom solar array articulation. Here, the pointing mechanism consists of a continuously rotating drive shaft that attaches the array assembly to the spacecraft body, and adjustable hinges that attach each solar panel to the drive shaft. Table 3 compares features of the two design alternatives and gives their respective advantages and disadvantages. Advantages of the first configuration, expecially the simpler array articulation, outweigh its disadvantages, and this concept is selected as the basis of subsequent discussions in this paper. Note that in both cases the articulation system keeps the array oriented normal to the Sun line, allowing the spacecraft to rotate relative to this orientation as required for thrust pointing in local horizontal direction, in or out of the orbit plane.
As shown in Figure 3, three ion thrusters (one and two spares) are placed in-line on a two-axis gimballed support structure, attached at the aft end, parallel to the transverse axis (zaxis). The distance from the center of mass is about $6 \mathrm{ft}$. such that a gimbal rotation of less than $10^{\circ}$ is needed for the laterally mounted spare thrusters to have their steady state thrust vectors pass through the c.m. when turned on after a failure of the central, first thruster. Gimballing the thruster support structure also is required to provide pitch and yaw attitude control torques that will be needed to compensate for thruster misalignment, and to be used for momentum wheel unloading. Roll control torques cannot be provided since only one thruster is used at any time. As a baseline, the use of magnetic torquers is assumed for this purpose. Further study is needed to show that this approach is suitable, making the addition of chemical roll control thrusters unnecessary.

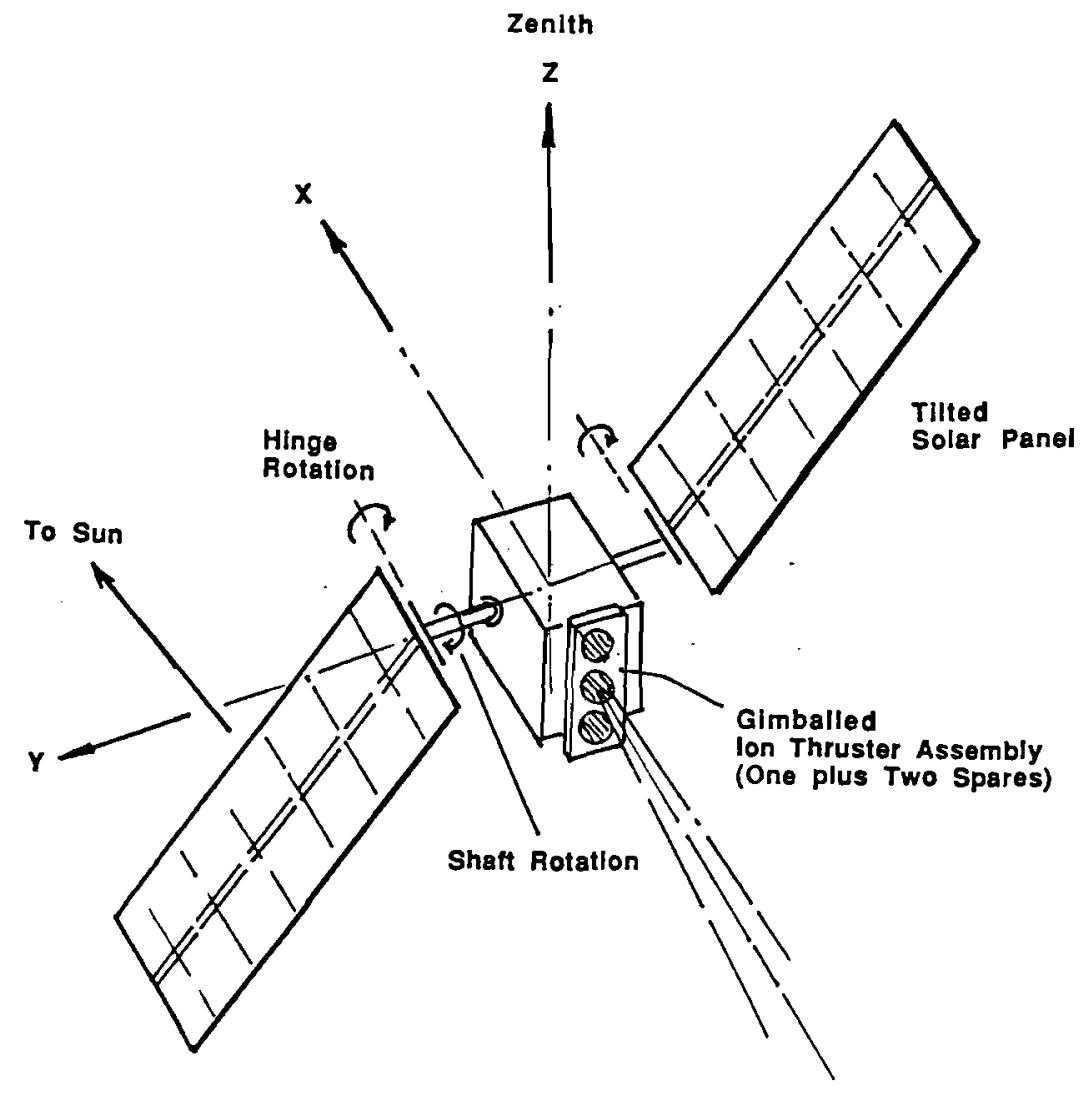

Fig. 4. Alternate Spacocraft Configuration. (Two-degree-of-freedom array articulation). 
Table 3 Comparison of Two Solar Array Rotatlon Alternatlves.

\begin{tabular}{|c|c|c|c|}
\hline $\begin{array}{c}\text { Array } \\
\text { Artlculation } \\
\text { Technlque }\end{array}$ & Prlnclpal Features & Advantages & Dlsadvantages \\
\hline $\begin{array}{l}\text { 1. Single Axis } \\
\text { (See Fig. 3) }\end{array}$ & $\begin{array}{l}\text { - S/C roll provides second } \\
\text { array rotation (not needed } \\
\text { if }|\beta| \leq 15^{\circ} \\
\text { - Solar panels remain } \perp \\
\text { Sunline (must rotate in } \\
\text { plane } \perp \text { Sunline) }\end{array}$ & $\begin{array}{l}\text { - Simpler than two-axis drive and } \\
\text { lower cost } \\
\text { - Minor dynamic interaction } \\
\text { - S/A cable wrap is suitable since } \\
\text { rotation less than } \pm 180^{\circ} \\
\text { - Gravity gradient can aid } S / C \text { roll } \\
\text { motion (see Ref. 14) }\end{array}$ & $\begin{array}{l}\text { - Large } S / C \text { roll motions } \\
\text { and rates for small | }|\beta| \\
\text { - EP thruster cannot } \\
\text { provide roll control } \\
\text { torque }\end{array}$ \\
\hline $\begin{array}{l}\text { 2. Two-Axis } \\
\text { (see Fig. 4) }\end{array}$ & $\begin{array}{l}\text { - Continuous rotation of } \\
\text { array assembly around S/C } \\
\text { pitch axis } \\
\text { - Generally, slow solar panel } \\
\text { hinge angle change (with } \\
\text { Sun angle } \beta \text { ) unless S/C } \\
\text { yaw angles are large }\end{array}$ & $\begin{array}{l}\text { - No S/C roll motion required } \\
\text { - Roll control requirements are } \\
\text { minor (dynamic interaction } \\
\text { effect) } \\
\text { - Smaller roll actuators than for } \\
\text { single-axis drive }\end{array}$ & $\begin{array}{l}\text { - More complex and } \\
\text { costly than single-axis } \\
\text { drive } \\
\text { - Needs S/A slip rings } \\
\text { - Continuous large } \\
\text { changes of moments } \\
\text { of inertia, dynamic } \\
\text { interactions }\end{array}$ \\
\hline
\end{tabular}

The thruster arrangement parallel to the $\mathrm{z}-$ axis has the advantage of minimizing thruster plume impingement on the solar panels, if one of the spare thrusters is used. It also avoids orienting the spacecraft at a pitch angle bias under this condition, imposing a yaw angle bias instead which has a lesser impact on the pointing control logic.

For attitude determination and autonomous navigation, the use of Dual Cone Scanners (DCS) built by Barnes Engineering is proposed, as mentioned before. They operate as Earth horizon sensors (see Figure 5) and also use Sun/Moon fans to determine the azimuth and elevation of the Sun and Moon centroids, for a total of seven distinct measurements (see Figure 6).

One DCS sensor is placed at the spacecraft front and one at the aft end, to provide continued Earth coverage, should one sensor field of view be blocked by the solar array. The selected transverse thruster arrangement eliminates adverse effects of spare thruster firing on the aft-mounted sensor.

The DCS output signals are processed onboard by the MANS (Microcosm Autonomous Navigation System) as explained in Reference 13. In Section 7 this attitude determination and navigation system is assessed in comparison with alternative implementations discussed in Ref. 2. Its principal advantages are lower cost and greater simplicity in design and operation.

\section{Solar Array Pointing}

The selected spacecraft configuration requires periodic roll motions in addition to solar array rotation to achieve optimal or nearoptimal Sun pointing, except at times when the Sun is in, or close to, the orbit plane (Ref. 14). For a spacecraft thrusting in horizontal direction along the velocity vector with its $y$ axis pointing in local vertical direction, the Sunline, in general appears to be moving continuously on a right circular cone, with a half-cone angle of $90^{\circ}-|\beta|$, where $\beta$ is the angle of the Sun's position relative to the orbit plane. The rate of this conical motion equals the orbital rotation rate. Figure 7 illustrates the apparent Sun line motion and shows the roll excursions that are required for solar array pointing. As dictated by the half-cone angle the maximum roll excursions also are $90^{\circ}-$ $|\beta|$. To simplify the sketch, the required panel rotation with a maximum of $90^{\circ}-|\beta|$ at zero roll angle is not shown. 


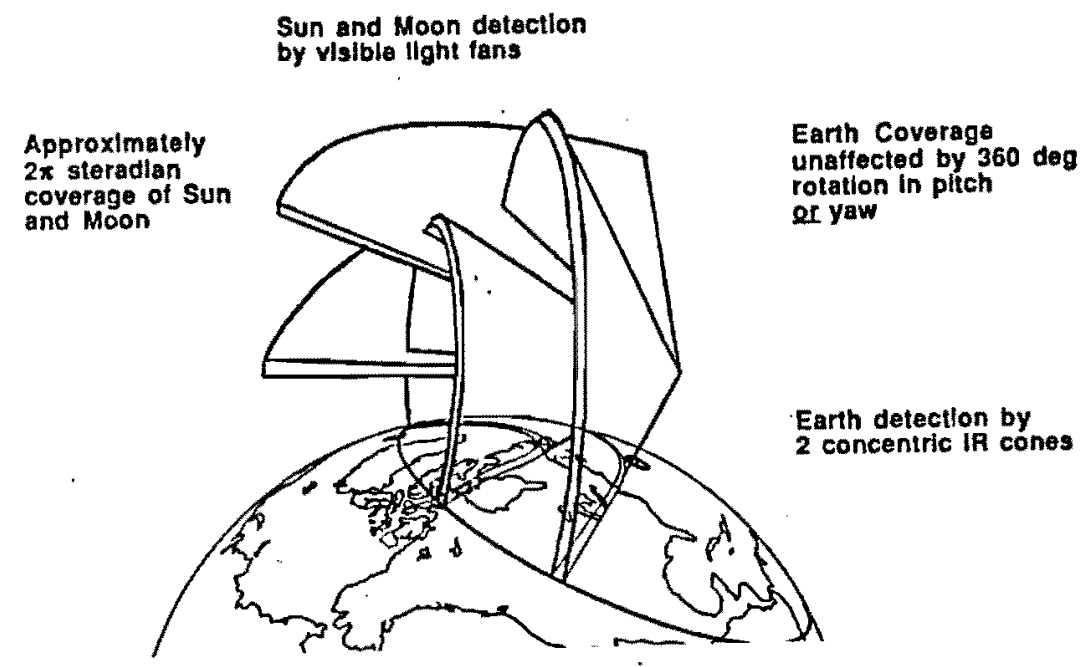

Fig. 5. DCS Fields of View and Operating Principle.

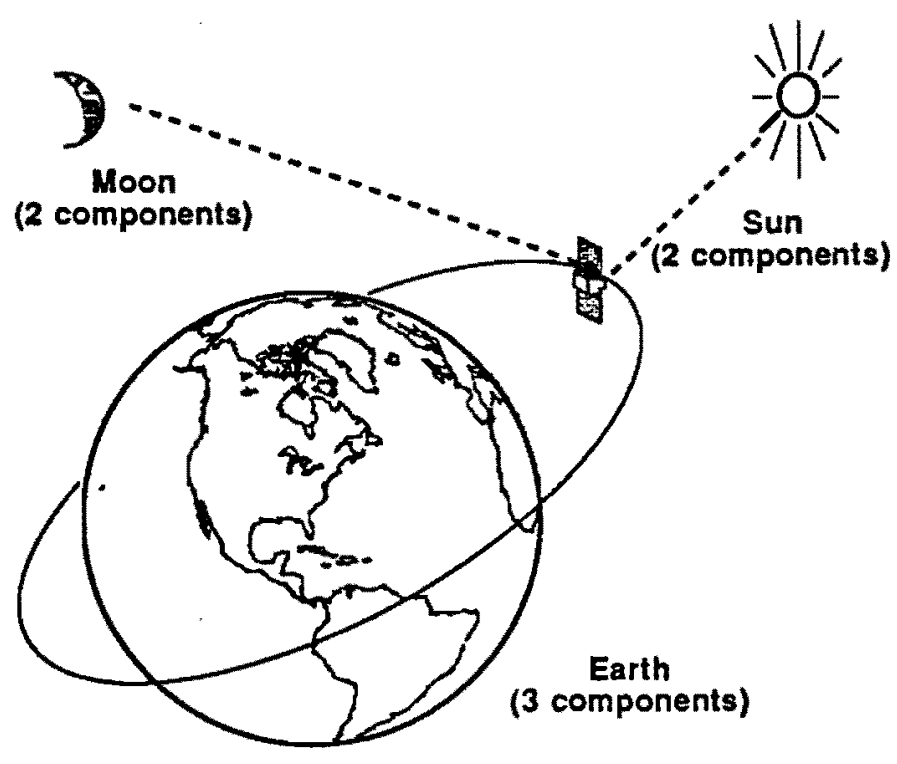

Fig. 6. Seven Independent Measurements (Earth, Sun, and Moon) Performed by DCS.

Figure 8 shows the evolution of the Sun angle, and the corresponding half-cone angle over the six-months interval between summer and winter solstice, for a typical low-altitude orbit. The time history is governed by the regression of the orbit's ascending node relative to the Sun and depends on orbit inclination and altitude.

Figure 9 depicts the geometry of apparent Sun motion as seen from the spacecraft in local LVLH coordinates, projected on a spacecraftcentered viewing sphere. The condition shown corresponds to thrusting along the velocity vector (thrust mode I). Solar array orientations at maximum roll angle are shown as dashed great circles. The shaded spherical triangle $A B C$ defines the roll angle, $\phi$, and the array rotation, $\alpha$, as functions of the Sun angle, $\beta$, and Sunline rotation angle, $v$, measured from nadir. They are given by

$$
\begin{aligned}
& \phi=\tan ^{-1}(\cos v / \tan \beta) \\
& \alpha=\sin ^{-1}(\sin v \cos \beta)
\end{aligned}
$$




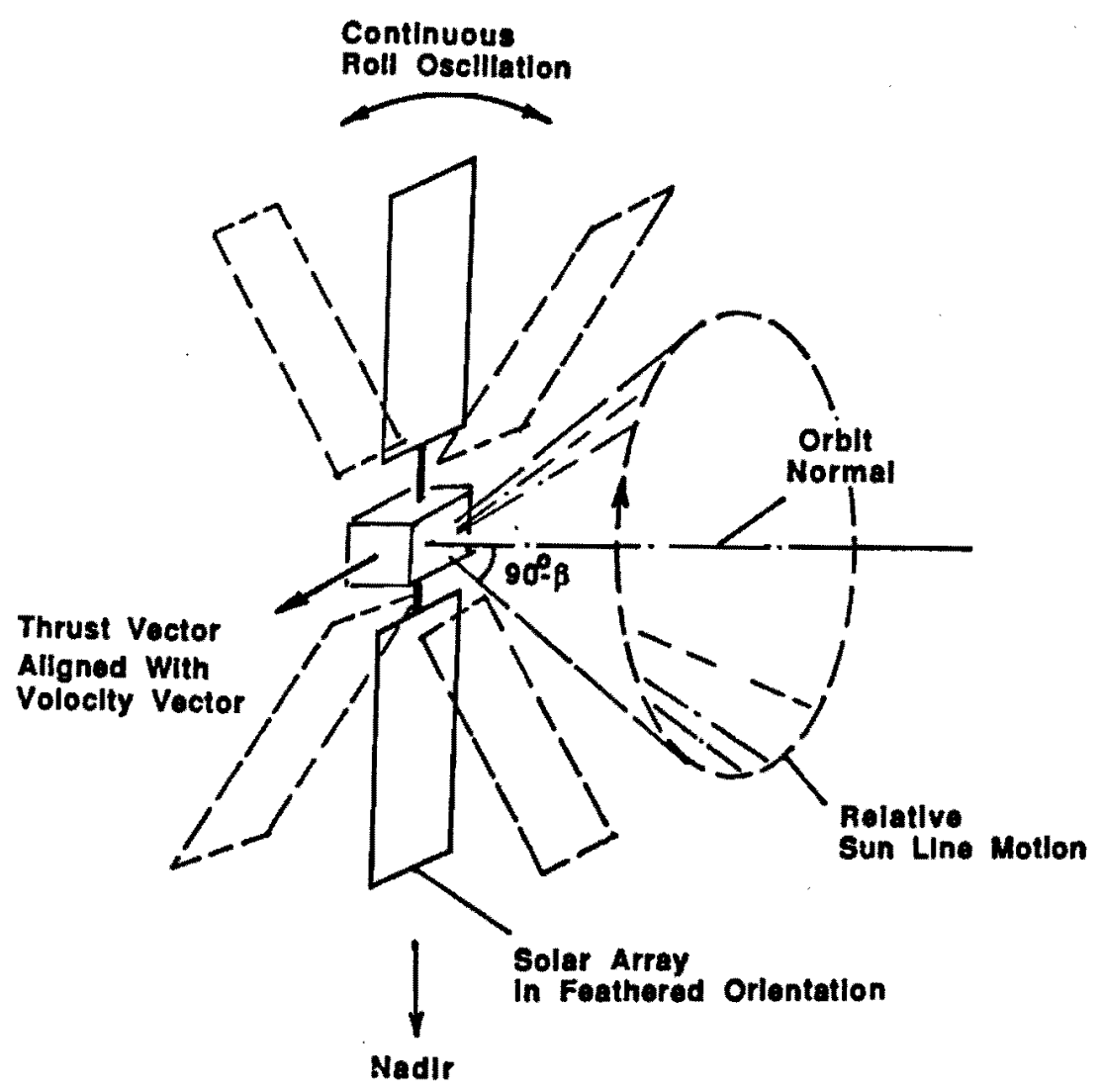

Fig. 7. Spacecraft Roll Oscillation for Sun Alignment.

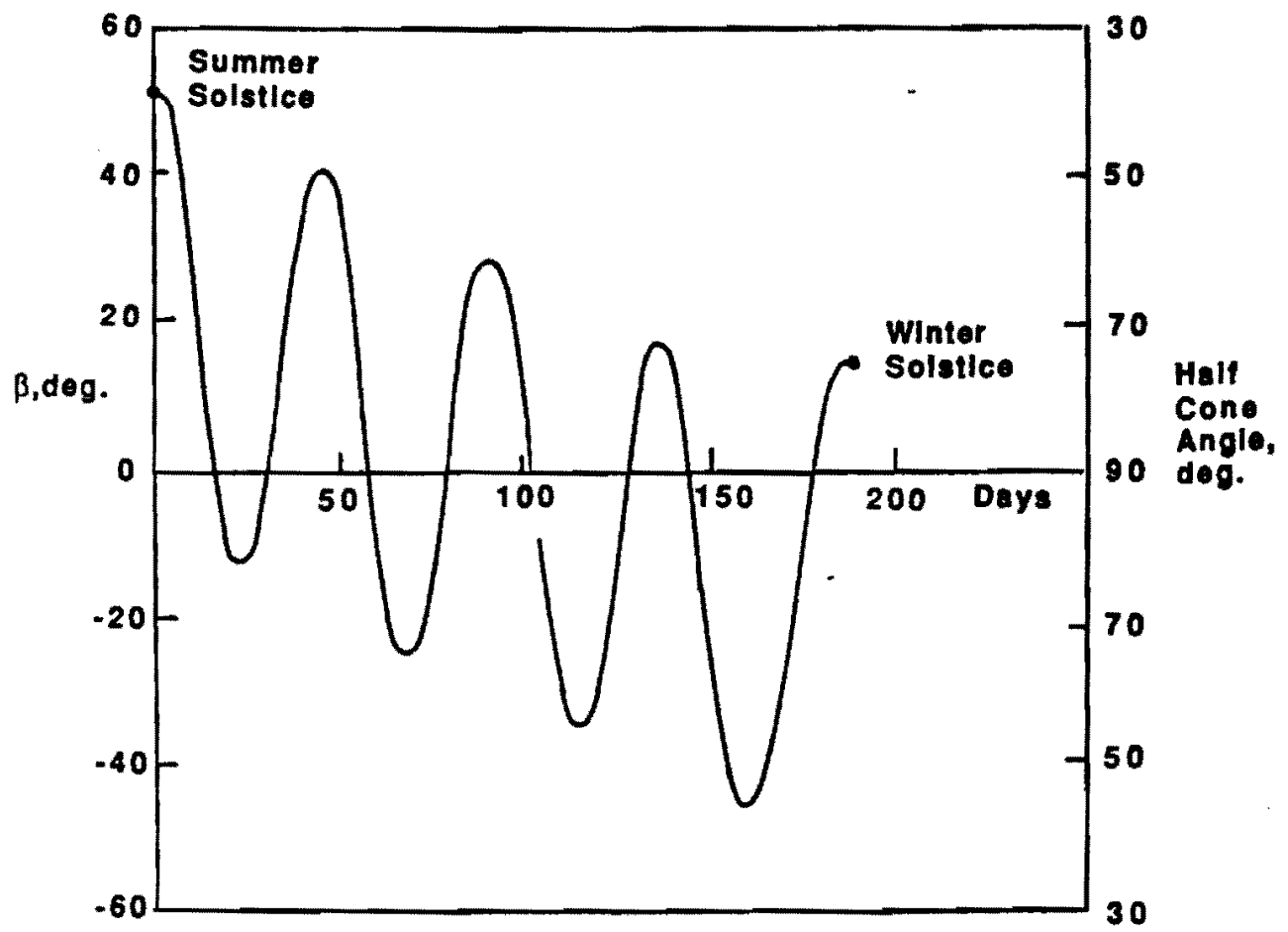

Fig. 8. Sun Angle Relative to Orbit Plane $\left(250 \mathrm{~km}\right.$ altitude, $28.5^{\circ}$ orbit). 


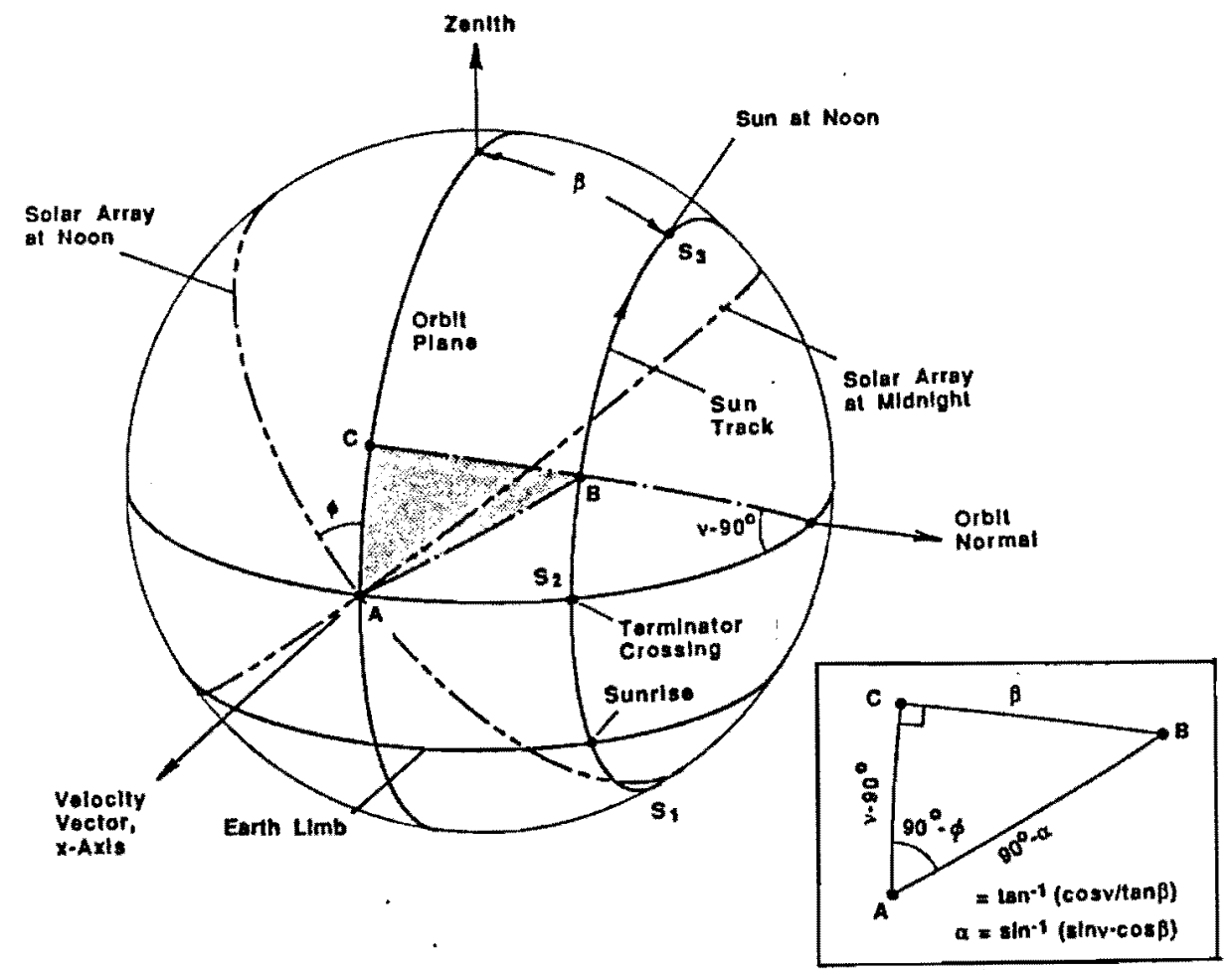

Fig. 9. Solar Array Pointing Geometry, Thrust Mode 1 (projected on spacecraft-centered viewing sphere).

Figure 10 shows the resulting $\phi$ and $\alpha$ time histories for several values of the Sun angle $\beta$. Maximum roll rates occur at $v=90^{\circ}$ and $270^{\circ}$, at times when the Sun crosses the horizontal plane. The maximum rates become excessively large for $\beta$ angles close to zero. To avoid this condition, which would require large roll actuator torques and could place excessive dynamic loads on the solar array structure, the spacecraft is held at a fixed $90^{\circ}$ roll angle and the solar panels are rotated at uniform rate whenever the Sun angle $|\beta|$ is below $15^{\circ}$. During these periods, which may last from a few days to several weeks (depending on altitude and orbit inclination), the maximum Sun misalignment angle is at most $15^{\circ}$, and the resulting solar power loss at most 3.4 percent.

The preceding discussion applies to spacecraft and solar array orientations during mission phases with in-plane, horizontal thrust vector pointing, Mode I. Periodic out-ofplane thrust vector orientations (Mode II) that are required to achieve plane changes modify the $\phi$ and $\alpha$ amplitudes required in Mode II, and the maximum roll rates, depending on the phasing of the yaw oscillations and their interaction with the Sun-tracking roll oscillations. Reference 2 presents an analysis of representative roll angle and roll-rate histories and indicates occasional needs for "snap roll" maneuvers, twice per revolution. This condition can be avoided by the $90^{\circ}$ roll orientation discussed above. At other times more nearly sinusoidal roll excursions are performed over limited time intervals with only a minor array power loss.

Roll oscillations required in both thrust modes can be sustained by exploiting gravity gradient torques, at a significant reduction of control actuator torque requirements. Gravity gradient "resonance" (see Reference 14) can be produced by "tuning" the spacecraft design through appropriately choosing the moment of inertia ratios $I_{y} / I_{x}$ and $I_{z} / I_{x}$. A detailed discussion exceeds the scope of this paper. Because of the inherently nonlinear character of the gravity gradient torque, the best tuned (natural) frequencies of the design are in the range of 0.6 to 0.8 of the orbital frequency. The resonance effect can reduce the magnitude of control torques required to maintain the large amplitude roll oscillations by a factor of 


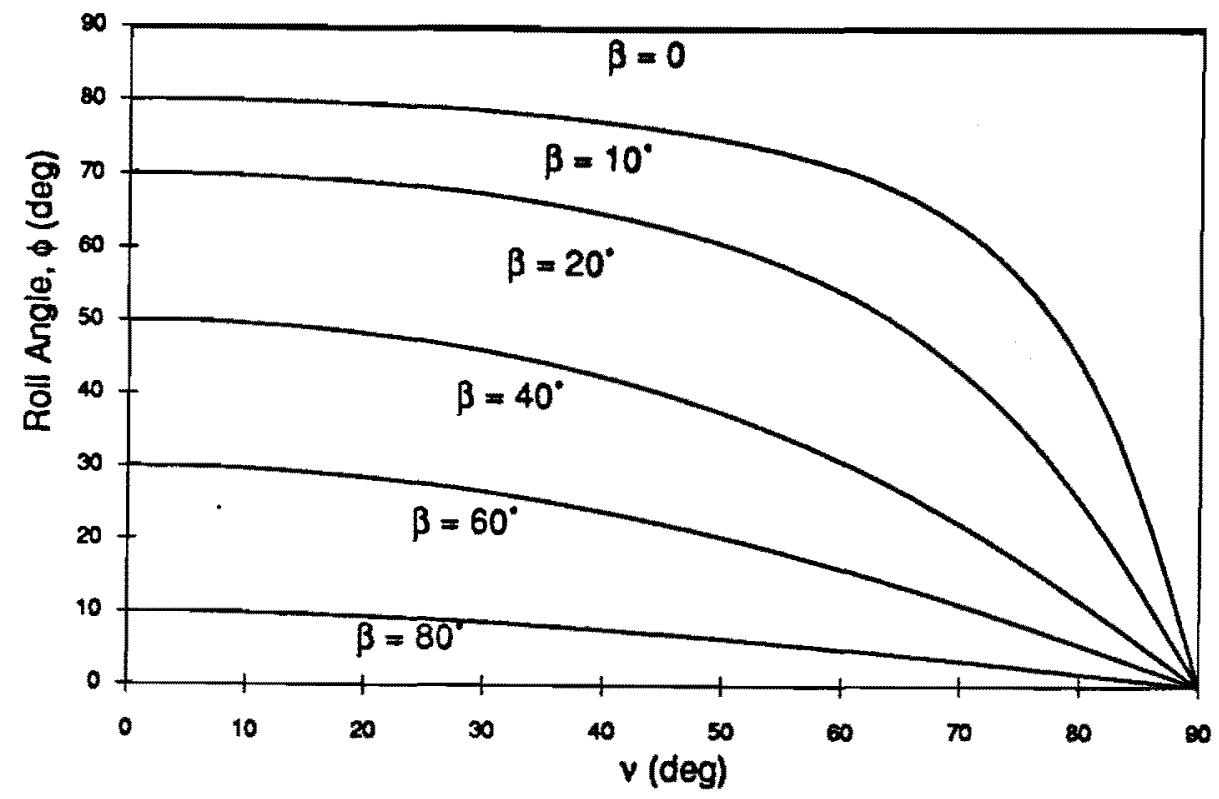

Fig. 102. Time Histories of Roll Angle $\phi$ and Solar Array Angle $\alpha$.

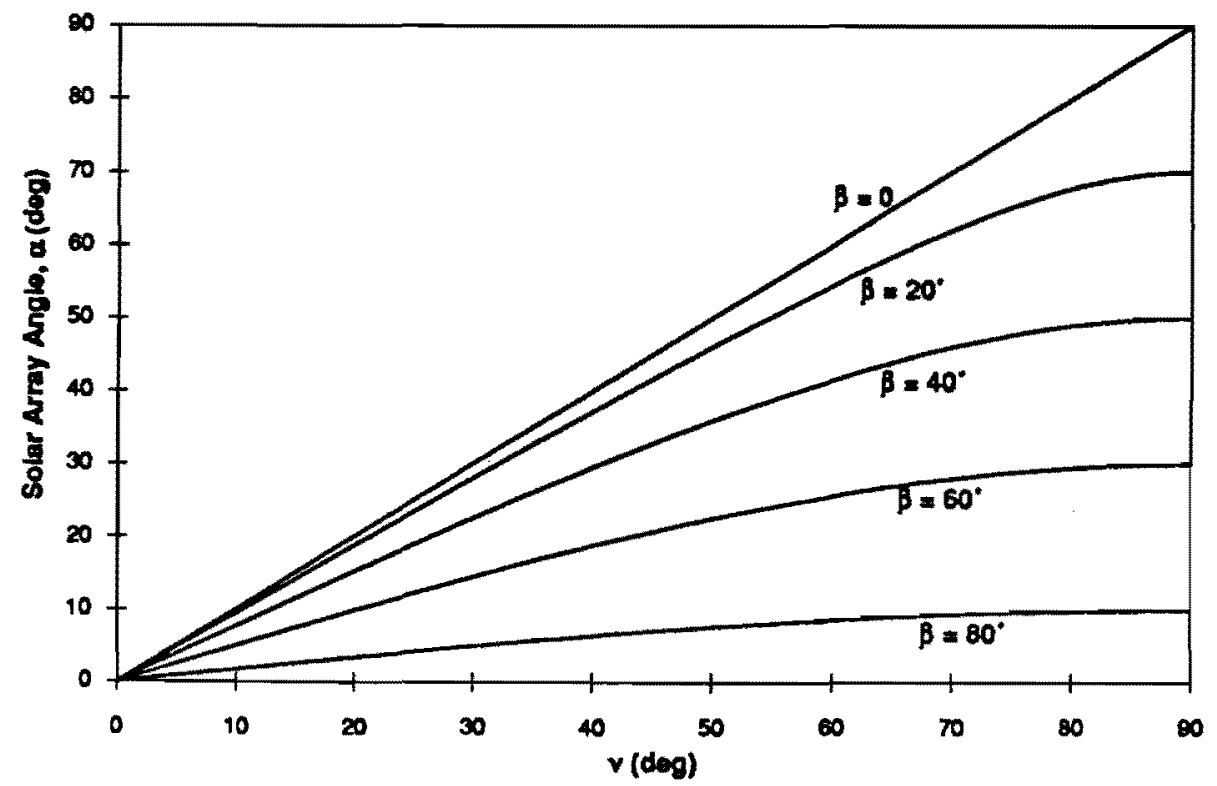

Fig. 10b. Time Histories of Roll Angle $\phi$ and Solar Array Angle $\alpha$.

2 to 8. The tuning effect remains invariant with altitude since the natural frequency and the orbital rate vary in the same proportion as the altitude is raised. Otherwise the tuning approach would be of little practical value.

Interactions between the uniform pitch rate and the desired roll motion are produced by natural, dynamic coupling of the two rotation effects. This interaction must be compensated throughout the mission, irrespective of the gravity gradient resonance effect discussed here.

The yaw oscillations required for out-ofplane thrusting cannot be aided in the same manner since for zero pitch angle the gravity gradient provides no yaw restoring torque. However, the essential point in this connection is that the electric thruster can produce the required yaw control, but not the roll control torques. 


\section{Solar Array Feathering at Low Altitude}

The technique of solar array feathering to reduce residual drag at low altitude and thereby enhance SEP thrust effectiveness is discussed in detail in Reference 14. Some assessment also is provided in Reference 2.

In principle, electric propulsion is not useful at altitudes where atmospheric drag effectively cancels the thrust force. At these altitudes an increase in solar array size would be of little help, as drag would increase nearly in the same proportion as thrust. An effective way to improve the thrust-to-drag ratio at this altitude is to point the array edgewise, in the direction parallel to the velocity vector. The drag reduction achievable in this manner is considerably greater than the average solar array power loss.

Fig. 11 shows drag deceleration versus altitude for a spacecraft with its solar array (a) fully exposed in an orientation normal to the atmospheric flow, and (b) pointed edgewise, in feathered orientation. With an assumed spacecraft weight of $550 \mathrm{lb}$, a drag coefficient $C_{D}=2$, and drag areas of 165 and $20 \mathrm{ft}^{2}$, respectively, the ballistic coefficient $W / C_{D} A$ changes from 1.67 to $13.8 \mathrm{lb} / \mathrm{ft}^{2}$ as a result of feathering, and the drag deceleration is reduced by a factor of 8.3 . At 30 percent average loss in thrust acceleration resulting from solar array Sun misalignment due to feathering, the drag reduction achieved in this example would lower the critical altitude from 170 to $135 \mathrm{nmi}$. The net drag reduction benefit will actually be smaller than these figures indicate, however, since the array is pointed normal to the atmospheric flow for optimum Sun exposure only during a part of the orbital revolution.

A more realistic quantitative comparison is obtained by evaluating the actual drag reduction and power loss as functions of orbit position $v$ and Sun orientation $\beta$ and averaging the results. Based on the pointing profile $\alpha(t)$ of an ideally Sun-tracking array (see Fig. 10), the instantaneous drag reduction is a function of $V$ and $\beta$ as shown in Fig. 12. The instantaneous power loss and the corresponding decrease in thrust are shown in Fig. 13 as functions of the same parameters. Averaging over a full revolution yields the drag reduction factor

$$
q_{D}=\left(D-D_{0}\right) / D_{0}
$$

and the corresponding thrust reduction factor

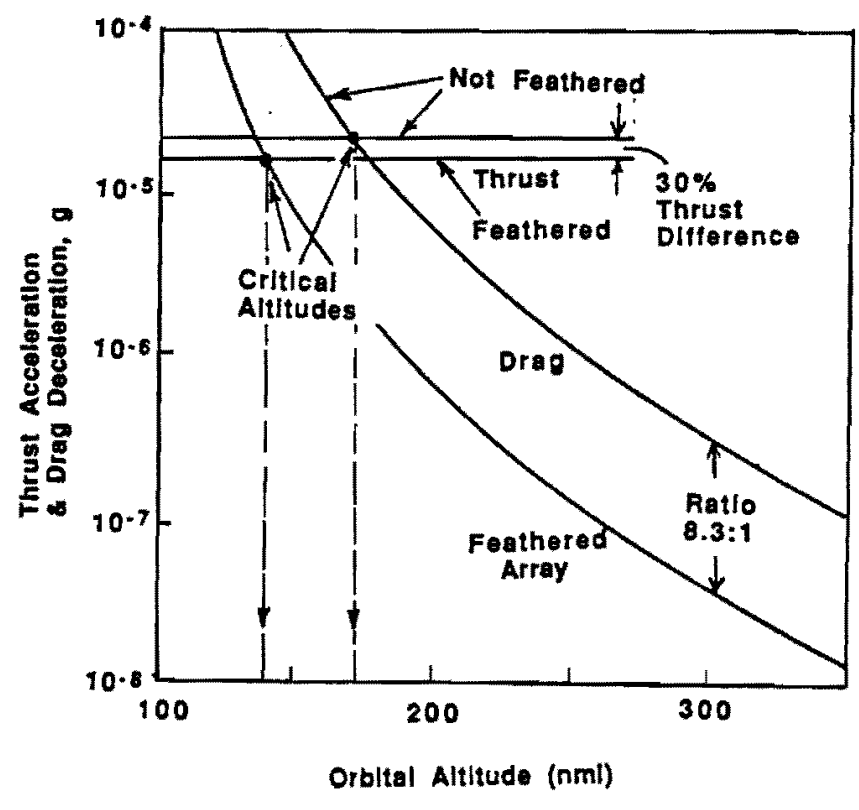

Fig. 11. Drag Deceleration vs. Altitude. 


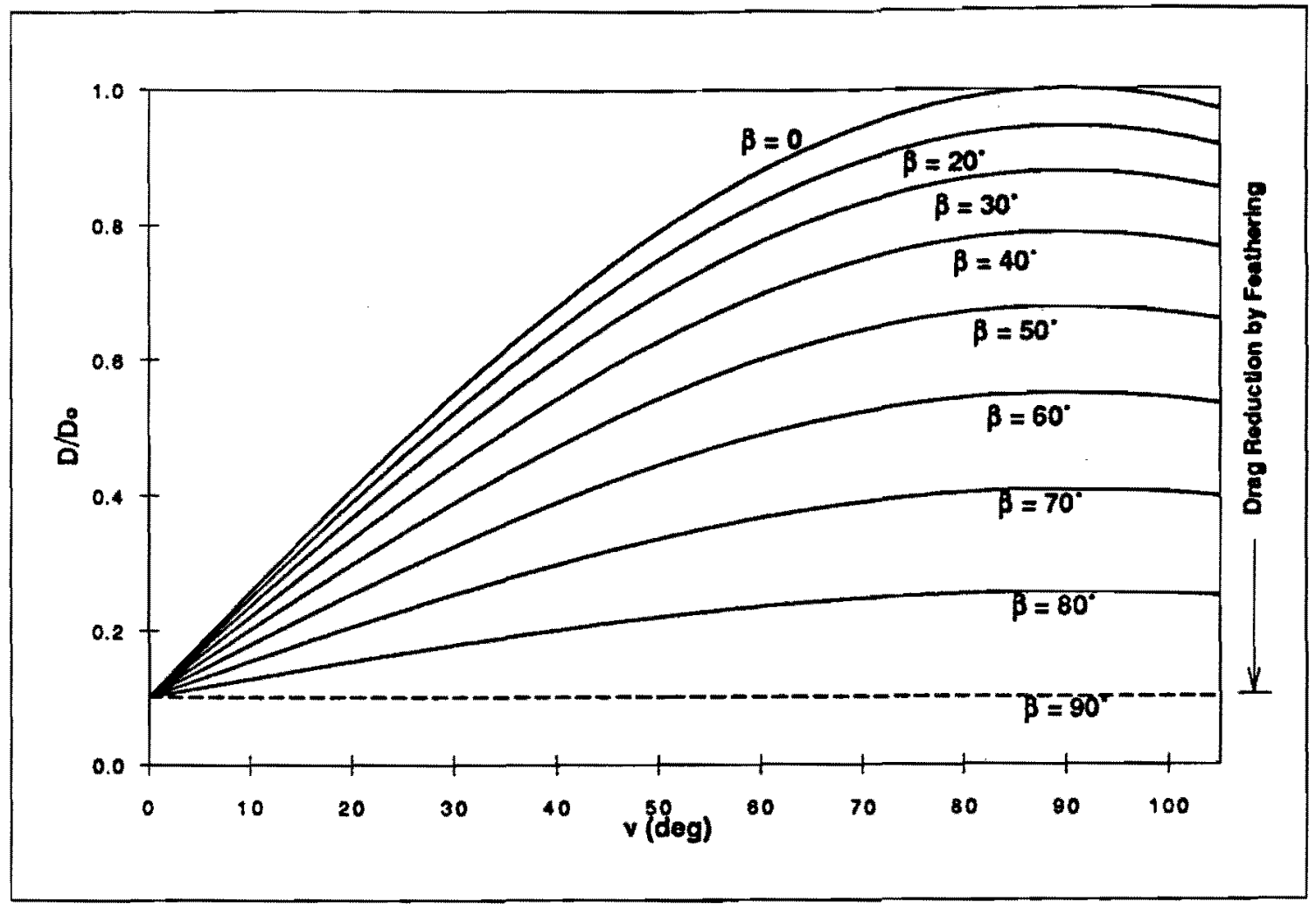

Fig. 12. Instantaneous Drag Variation with $\nu$ and $\beta$ due to Arrav Feathering.

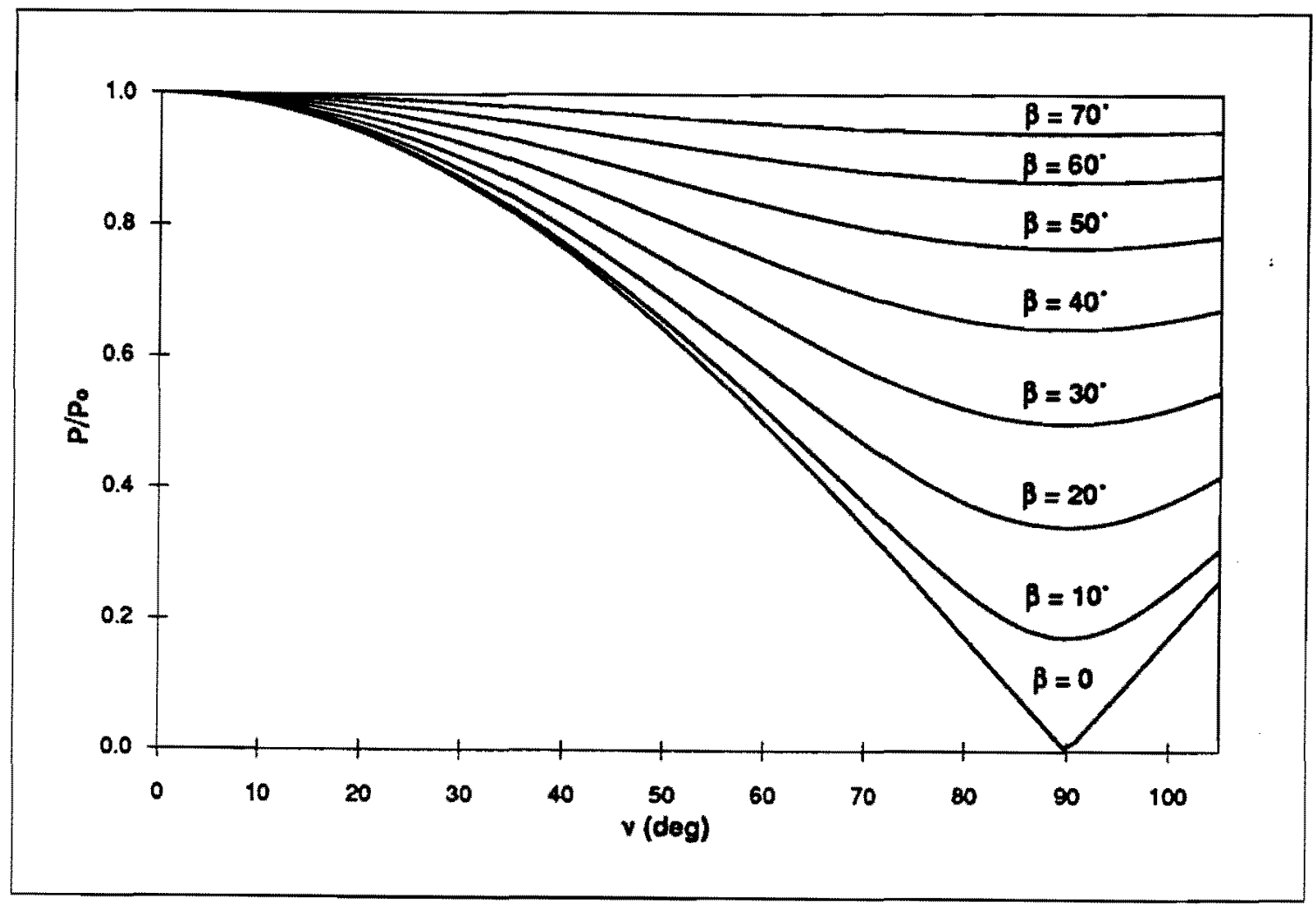

Fig. 13. Instantaneous Relative Power (and Thrust Force) Variation with $v$ and $\beta$ due to Array Feathering. 


$$
q_{F}=\left(F-F_{0}\right) / F_{0}
$$

as functions of $\beta$ (see Figure 14). The effect of solar eclipse at low orbital altitude was taken into account in deriving these results.

The ratio $m=q_{F} / q_{D}$, also plotted in Figure 14, indicates the effectiveness of feathering in terms of the increase in thrust-todrag ratio compared with the nominal, nonfeathered, pointing mode. The two thrust-todrag ratios are related to each other by

$$
\frac{F_{1}}{D_{1}}=\frac{q_{F} F_{o}}{q_{D} D_{o}}=m \frac{F_{o}}{D_{o}}
$$

The subscripts 1 and $o$ refer to the feathered and non-feathered orientations, respectively. With $m$ depending strongly on $\beta$, it is apparent from Fig. 14 that feathering is most effective in the 0 to $60^{\circ}$ Sun angle range. The maximum $m$-value (4.64) is located at $\beta=35^{\circ}$. The ratio decreases to 1 at $\beta=90^{\circ}$.

In terms of mission performance, the effect of feathering is expressed by the thrust time required to achieve a specific $\Delta V$ increment in

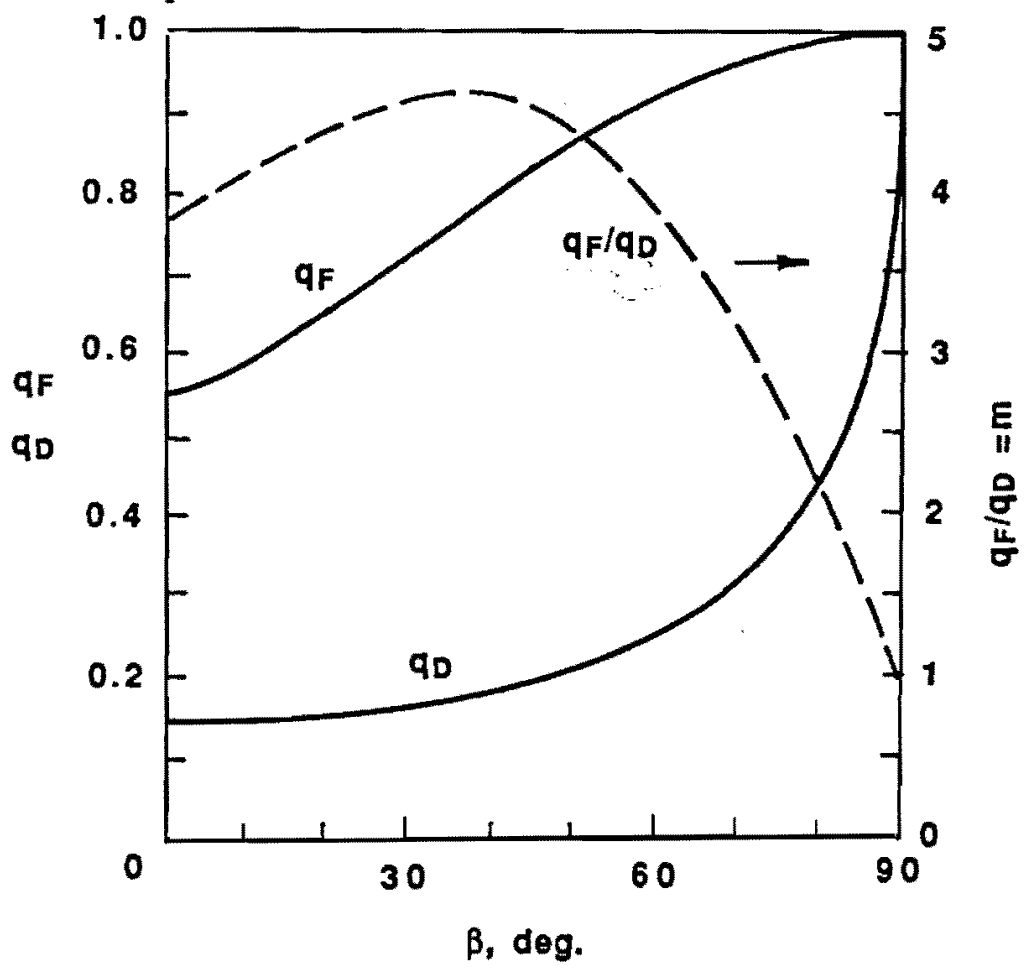

Fig. 14. Average Thrust and Drag Reduction Factors $q_{F}$ and $q_{D}$ and Ratio $m$ vs. $\beta$ due to Array Feathering. the presence of drag compared with nonfeathered orientation. The following examples from Ref. 14 illustrate thrust time reductions achievable by feathering. The thrust time for a $100-\mathrm{nmi}$ altitude increase requiring a $350-\mathrm{ft} / \mathrm{s}$ velocity increment is considered. A nominal thrust acceleration of $10 \mathrm{micro}-\mathrm{g}$ and an $F_{d} D_{0}$ ratio $n=1.2$ are assumed. The ideal thrust time in the absence of drag is given by

$$
t_{i}=\Delta V / 10^{-5} \mathrm{~g}=12.6 \text { days }
$$

The thrust time in the non-feathered mode would be $t_{0}=6 \times 12.6=75.5$ days. With array feathering the thrust time is reduced to

$$
t_{1}=0.39=29.4 \text { days at } \beta=0^{\circ}
$$

and to

$$
t_{1}=0.22=17.4 \text { days at } \beta=60^{\circ}
$$

The thrust time reductions derived for the above examples also reflect a proportional reduction of propellant expenditure. 
These results indicate that even near the critical altitude at very low nominal thrust-todrag ratios, use of feathering permits starting the low-thrust mission without requiring an initial chemical propulsion boost. Therefore, in the proposed demonstration mission where total thrust time is not of critical concern, addition of a chemical propulsion subsystem is unnecessary, and the ascent can start at nominal, low Shuttle altitudes.

\section{Guidance, Navigation and Control Alternatives}

Several navigation, guidance and control alternatives are available and were investigated by Zondervan et al. (Reference 15). Reference 2 presents a summary. Navigation and attitude sensing devices and techniques to be used in various combinations include an Inertial Measurement Unit (IMU), the Global Positioning System (GPS), and Earth sensor (ES), a star sensor and the Dual Cone Scanner (DCS). The latter, which was described in Section 3 but not included in Ref. 2 and 15, is sufficient by itself to provide the required orbit determination, satellite position and attitude data autonomously, thereby minimizing the need for ground support. This sensor and the associated Microcosm Autonomous Navigation System is simpler and more economical for use on the proposed SEP spacecraft than the other alternatives mentioned. Since the mission does not have a target position or rendezvous objective at its destination, it is less demanding in guidance accuracy than operational EP orbit transfer missions (Reference 1).

Table 4 summarizes navigation and attitude errors at the end of one orbit, as determined in Ref. 2 for the various sensor combinations and adding those of DCS/MANS. An estimate of accuracies required in the proposed demonstration mission is included in the table. The latter system's accuracy is lower than that of other sensor combinations but is considered sufficient for this and future EP missions.

Table 4. Navigatlon and Attltude Errors (1 sigma) at End of One Orblt for Varlous Sensor Comblnations

\begin{tabular}{|c|c|c|c|c|c|}
\hline $\begin{array}{c}\text { Coordinate } \\
\text { Axis }\end{array}$ & GPS(1) & GPS + SS(1) & GPS + SS(1) & $E S+S S^{(1)}$ & MANS ${ }^{(2)}$ \\
\hline \multicolumn{6}{|c|}{ POSITION (ft) } \\
\hline East & 101 & 90 & 92 & 108,500 & \\
\hline North & 87 & 58 & 59 & 108,800 & 109 \\
\hline Up & 890 & 454 & 477 & 8,344 & \\
\hline \multicolumn{6}{|c|}{ VELOCITY (ft/sec) } \\
\hline East & 0.05 & 0.03 & 0.03 & 0.61 & \\
\hline North & 0.003 & 0.003 & 0.003 & 0.02 & 0.437 \\
\hline Up & 0.08 & 0.02 & 0.03 & 7.9 & \\
\hline \multicolumn{6}{|c|}{ ATTITUDE (arc sec) } \\
\hline East & 165 & 108 & 120 & 108 & \\
\hline North & 7.914 & 108 & 120 & 108 & 36 \\
\hline Up & 276 & 108 & 136 & 108 & \\
\hline
\end{tabular}

(1) Based on data from DeVincenci, et.al. (Ref. 2)

(2) Based on use of 2 DCSs with Microcosm Autonomous Navigation System. Errors in three axis directions approximately equal 
Note that GPS operation in its simplest form, without an IMU and added Sun or Earth sensor does not readily provide attitude measurements, while these measurements are an inherent part of the DCS data. For other missions future development promises to provide spacecraft attitude data directly from GPS signals, by signal processing. However, in this mission potential interference from the large solar arrays in the signal path limits the applicability of this attitude measurement technique. Also, as was mentioned previously, on ascending to the GPS orbit altitude and above, the number of GPS satellites accessible by the user at any time during the orbit period decreases to an average of one or less than one.

Guidance accuracy requirements for lowthrust missions in general are modest, since any accruing errors can be readily corrected during subsequent continuous thrusting without significant extra propellant expenditure. Reference 2 lists four guidance function alternatives for ELITE and recommends the selection of the "approximate closed form (analytical) technique," because of its easy implementation. Only minor propellant penalties accruing from the use of this technique are anticipated. Mission simulations indicate that a propellant margin of 2.5 percent is more than adequate with steering bias errors of $10^{\circ}$ or less.

\section{Summary and Conclusions}

A small, low-powered SEP technology demonstration satellite mission with spiral ascent capability from LEO to GEO altitude appears to be of timely interest as a stepping stone in the evolution of larger, more costly SEP vehicles currently being projected.

With a 10 -mlb thrust ion engine powered by about $1 \mathrm{~kW}\left(I_{s p}=3000 \mathrm{~s}\right.$, total efficiency 65 percent) and providing a $20 \mathrm{-micro}-\mathrm{g}$ average thrust acceleration, a 300-day ascent to geosynchronous orbit is achievable. The small size of the vehicle, using elements of existing small satellite designs, is keyed to major savings in system development and launch cost, as well as development and test time reduction.

Performance improvement by increasing the satellite power level yields only dimini- shing returns: doubling the power level reduces the ascent time by 30 percent, and tripling the power reduces it by 40 percent, respectively, to 210 days and 180 days. This generic fact is true for SEP spacecraft of any size.

The proposed low-cost demonstration mission can serve as a precursor to later, more demanding, demonstration flights, such as the ELITE SEP technology demonstration mission, and ultimately to operational missions, using EP orbit transfer vehicles in Earth vicinity or deep space.

Autonomous navigation is essential to relieve ground support requirements in any continuous-thrust, long-duration mission. This applies to the proposed demonstration as well as to future, more demanding, missions currently being projected by the US Air Force. The Microcosm Autonomous Navigation System is an excellent low-cost and simple candidate to perform this function.

Optimal solar array pointing is essential for power economy of any SEP vehicle, including the proposed low-cost demonstration spacecraft. The required continuous roll oscillations of the vehicle can be effectively sustained with the aid of the gravity gradient resonance effect, given appropriate "tuning" of the moment-of-inertia ratios. The effect remains invariant with changing altitude.

Solar array feathering at low altitudes effectively increases the average thrust-to-drag ratio above critically low values that would preclude SEP operation in this region. With this technique, the demonstration mission can be started at a low altitude consistent with Shuttle launch without a higher-thrust chemical propulsion boost. This permits additional cost and weight savings.

All factors investigated thus far point to a practical and economical early mission with the objective of demonstrating SEP system functioning, performance characteristics, thrust modes, pointing modes for optimal power, as well as monitoring SEP system performance and observing interaction effects. Further study of this mission class is recommended with the goal of leading to an early implementation.

Acknowledgement

The author gratefully acknowledges 
valuable suggestions from his colleagues at Microcosm, Inc. and particularly those from Dr. James $R$ Wertz. In addition, he has received helpful comments from Messrs. David Byers, NASA/Lewis Research Center, Sid Zafran and Dr. C. L. Dailey of TRW Space \& Technology Group, and Mr. Richard Warner of Aero-Astro, Inc., Reston, VA.

\section{References}

1. EPOTV (Phase II), Final Report, Prepared by Microcosm, Inc., Torrance, CA, under USAF Space Division Contract F04701-88-C-0045. March 1991.

2. D.L. DeVincenzi, et al, "Elite System Analysis," AIAA Paper 90-2530, AIAA/DGLR/JSASS, $21 \mathrm{st}$ International Electric Propulsion Conference, Orlando, FL. July 18-20.

3. R.H. Cohen, et al., "Preliminary Concepts for a Solar Electric OrbitRaising Experiment," AIAA Paper 89-, AIAA/ASME/SAE/ASEE 25th Joint Propulsion Conference, Monterey, CA. July 1989.

4. E. Stuhlinger, Ion Propulsion for Space Flight, McGraw Hill, New York, NY 1964.

5. H.R Kaufman, RS. Robinson, "Electric Thruster Performance for Orbit-Raising and Maneuvering ${ }^{n}$ in Orbit-Raising and Maneuvering Propulsion: Research Status and Needs, L.H. Caveny, Ed., Progress in Astronautics and Aeronautics, Volume 89, AIAA, New York, NY 1984.

6. P.J. Wilbur, "Electrostatic Thruster Capabilities for Orbit-Raising and Maneuvering Missions," in Orbit-Raising and Maneuvering Propulsion: Research Status and Needs, L.H. Caveny, Ed., Progress in Astronautics and Aeronautics, Volume 89, AIAA, New York, NY, 1984.

7. R.D. Lorenz, "Electric Propulsion for Small Spacecraft," Proc. of the Third
Annual AIAA/Utah State University Conference on Small Satellites, Logan, UT, Sept. 1989.

8. T. N. Edelbaum, "Propulsion Requirements for Controllable Satellites," ARS Joumah Vol. 31, No. 8, Aug. 1961.

9. W.E. Moeckel, Trajectories with Constant Tangential Thrust in Central Gravitational Fields, NASA TR-R-53, 1960.

10. H.F. Meissinger, "Size, Performance and Cost Trades of Large Solar Electric Propulsion Systems," AIAA Paper 78697, AIAA/DGLR 13th International Electric Propulsion Conference, San Diego, CA April 1978.

11. B. Raab, "Modular Small Satellite Design for Responsive Tactical Applications," Proc. of the 4th Annual AIAA/USU Conference on Small Satellites, Utah State Univ., Logan, UT, Aug. 1990.

12. J.P. Andrew, et al., "Lone Star-A Small Communication Satellite for Texas," Proc. of the 4th Annual AIAA/USU Conference on Small Satellites, Utah State University, Logan, UT, Aug. 1990.

13. F. Tai, P.D. Noerdlinger, "A Low-Cost Autonomous Navigation System, ${ }^{n}$ AAS Paper 89-001, 12th Annual AAS Guidance and Control Conference, Keystone, CO, Feb. 1989.

14. H.F. Meissinger, C.L. Dailey, M.E. Valgora, "Optimal Sun-Alignment of Large Solar Arrays in Electric Propulsion Spacecraft," AIAA Paper 82-1898, AIAA/JSASS/DGLR 16th International Electric Propulsion Conference, New Orleans, LA, Nov. 1982.

15. K.P. Zondervan, et al., "Guidance, Navigation, and Control Trades for an Electric Orbit Transfer Vehicle," AIAA Paper 90-3458-CP, AIAA Guidance, Navigation and Control Conference, Portland, OR, Aug. 1990. 